\title{
A palavra como lócus de análise da variação fonético-fonológica
}

\author{
The word as a locus for the analysis of phonetic-phonological variation
}

\author{
Carine Haupt \\ Fundação Universidade Federal do Tocantins - Porto Nacional - Tocantins - Brasil
}

\begin{abstract}
Resumo: Este artigo apresenta dados coletados no corpus do NILC com os objetivos de discutir a pertinência de analisar fenômenos de variação fonética tomando como lócus de análise a palavra (considerando como exemplo a variação entre ditongo e monotongo) e fornecer dados acerca dos padrões em que se encontram os ditongos na língua portuguesa. Tomamos como base teórica a Fonologia de Uso e a Teoria dos Exemplares. São abordagens multirrepresentacionais, pois nelas nega-se o preceito de que as representações fonológicas são categóricas e discretas. Além disso, as representações são gerenciadas pelo uso, e não inatas. Assim, os dados coletados evidenciam que considerar a palavra tem papel fundamental nos resultados dos estudos de variação fonético-fonológica.
\end{abstract}

Palavras-chave: Ditongo; Monotongo; Variação; Palavra; Fonologia de Uso

\begin{abstract}
This article presents data collected in the NILC corpus with the objective of discussing the relevance of analyzing the phenomena phonetic variation taking the word as locus of analysis (considering as example the variation between diphthong and monophthong) and providing data about the patterns in which they are diphthongs in Portuguese. We take as theoretical basis the Phonology of Use and Theory of Exemplars. They are multi-representational approaches, therefore they deny the precept that phonological representations are discrete and categorical. Furthermore, the representations are managed by use, not innate. Thus, the data collected show that the word plays a fundamental role in the results of study of phonetic-phonological variation.
\end{abstract}

Keywords: Diphthong; Monophthong; Variation; Word; Phonology of Use

\section{Introdução}

O presente artigo objetiva apresentar argumentos a favor de se estudar a variação fonológica tomando como lócus a palavra. Nossa discussão pauta-se nos pressupostos da Fonologia de Uso (BYBEE, 2000, 2001, 2002, 2003) e na Teoria dos Exemplares (JOHNSON, 1967, PIERREHUMBERT, 2001), cujas abordagens contrastam com abordagens tradicionais de Fonologia, tais como a estruturalista e a gerativista, que tomam o segmento como unidade de análise. Os exemplos e dados que fundamentam os nossos argumentos circunscrevemse na alternância entre monotongo e ditongo de formas tradicionalmente concebidas como ditongos decrescentes formados com a semivogal $[\mathrm{I}]$ ], fenômeno amplamente estudado em várias regiões do Brasil. O corpus utilizado para a análise é o do NILC (Núcleo Institucional de Linguística Computacional). Esse corpus se mostrou adequado para os nossos propósitos devido sua extensão (aproximadamente 35 milhões de palavras) e variedade de gêneros textuais que o compõem. A exposição tem o objetivo também de fornecer dados a respeito dos padrões em que se encontram os ditongos na língua portuguesa.

Um dos pressupostos da Fonologia de Uso é de que o uso afeta as representações mentais. Faremos, então, este recorte: concentraremos a nossa análise na frequência de ocorrência e de tipo (conceitos explicados a seguir) de palavras com ditongos para discutir como elas podem interferir no uso variado entre ditongo e monotongo e até na mudança. Assim, organizamos o artigo em seções. $\mathrm{Na}$ primeira, esclarecemos os conceitos que usaremos no decorrer da exposição, bem como alguns pontos de contraste entre a Fonologia de Uso e modelos tradicionais de Fonologia. Na segunda seção, apresentaremos os resultados de alguns estudos sobre a alternância entre ditongo e monotongo e os dados referentes às frequências do corpus do NILC. Na última seção, tomaremos os dados apresentados para tecer nossa discussão e conclusões. 


\section{A representação mental na Fonologia de Uso}

A Fonologia de Uso e a Teoria dos Exemplares podem ser entendidas como teorias multirrepresentacionais de Fonologia (CRISTÓFARO-SILVA e GOMES, 2004) por não compartilharem a concepção de que as representações linguísticas são discretas e categóricas. Contrariamente às teorias tradicionais, como a Fonologia Estruturalista, Gerativista e Autossegmental, incorpora o detalhe e a gradualidade fonética na organização das categorias sonoras. Outro contraste essencial é o fato de que o conhecimento linguístico que era tido, nas teorias tradicionais, como inato e gerenciado pela Gramática Universal, passa a ser visto como baseado no uso e gerenciado probalisticamente em conexões organizadas em redes (CRISTÓFARO-SILVA e GOMES, 2004, p. 162). Vejamos, a seguir, mais detalhes sobre a proposta de uma fonologia baseada no uso, de acordo com Bybee (2001, p. 6-7):

1. a experiência afeta a representação, isto é, palavras e construções mais frequentes são mais fortes no sentido de que são mais facilmente acessadas, enquanto as menos frequentes tornam-se mais fracas, podendo até ser esquecidas. A força lexical de uma palavra pode mudar à medida que é mais ou menos usada em diferentes contextos. Essa é a principal diferença entre as abordagens modulares em que as representações, regras ou restrições são estáticas e todas as regras ou representações do mesmo componente têm o mesmo status;

2. a categorização é baseada na identidade e similaridade. Diferentes tipos de relações entre os objetos linguísticos podem ocorrer, como, por exemplo, a relação entre duas amostras fonéticas de uma mesma palavra, relação de um mesmo morfema em diferentes palavras, a relação entre dois fones similares em diferentes palavras no mesmo contexto ou não;

3. generalizações da forma não são separadas das representações armazenadas, mas sim emergem diretamente delas. Isso significa dizer que as generalizações são expressas como relações entre formas, baseadas nas similaridades fonéticas e/ou semânticas;

4. a organização lexical fornece generalizações e segmentações para os vários graus de abstração e generalidade, uma vez que unidades tais como morfema, segmentos ou sílabas emergem das relações de similaridade que organizam as representações.

Ao se considerar que as generalizações emergem do uso, não se pode mais separar léxico de gramática, uma vez que é o uso de palavras ou estruturas sintáticas cristalizadas (chunks) que vão determinar a emergência das categorias. Tomemos como exemplo a emergência de morfemas: uma vez que as palavras são relacionadas em função de sua similaridade fonética e semântica e organizadas em redes, os morfemas emergem naturalmente dessas conexões. Assim, não há, em modelos multirrepresentacionais, listas de fonemas na gramática (CRISTÓFARO-SILVA e GOMES, 2004, p. 167).

A Teoria dos Exemplares pode ser vista como um modelo representacional para a Fonologia de Uso. Nessa teoria, os exemplares com mais similaridades vão se agrupando e formando nuvens. Quanto mais um exemplar é usado, mais forte ele será, adquirindo características de elemento prototípico. Quanto menos usado, mais fraco o exemplar tornar-se-á, podendo até ser esquecido, o que caracteriza uma mudança. As mudanças nos modelos multirrepresentacionais são graduais, tanto fonética quanto lexicalmente.

Uma vez que a gramática se constrói a partir das representações gerenciadas probalisticamente, decorrentes das experiências do falante com a língua, que é inerentemente dinâmica por estar em constante variação e mudança, a frequência dessas experiências é central para essa teoria. São duas as categorias de frequência que nos auxiliam a explicar a variação e as mudanças sonoras: a frequência de ocorrência (ou de uso) e a frequência tipo. A primeira refere-se ao uso de determinado item lexical. Itens muito frequentes tendem a gerar o efeito da automatização, resultando em redução quando há contextos fonéticos propícios. Muitos estudos já atestaram que palavras mais frequentes são atingidas primeiramente em fenômenos de redução foneticamente motivados (Van Bergen, 1995; Gregory et. al., 1999; Bybee, 2001; Jurafsky et. al., 2001 apud BYBEE, 2002). A alta frequência de um item lexical pode também gerar o efeito contrário, isto é, tornar o item menos suscetível à variação, preservando sua forma, como, por exemplo, em formas irregulares, tais como a do verbo 'ser' e construções idiomáticas. Quando não há motivação fonética, a variação pode ser decorrente de analogias com exemplares mais frequentes ou de reanálises, seja no nível sintático, morfológico ou fonológico (PHILLIPS, 1984).

A segunda categoria de frequência, a frequência tipo, refere-se à frequência de determinado padrão na língua. Ela está associada à produtividade de determinado padrão e é usada para outros tipos de análises, como, por exemplo, referentes às generalizações fonotáticas. A frequência tipo, portanto, determina a produtividade de padrões fonológicos, morfológicos e sintáticos, porque quanto maior o número de itens para uma determinada categoria, mais gerais serão seus traços e mais facilmente se estenderão a outros itens (inclusive novos), promovendo, assim, generalizações.

Uma vez que consideramos que a experiência do falante, ou seja, a fala, determina as representações mentais, não é mais possível adotar a clássica divisão entre Fonética e Fonologia. Na Fonologia de Uso e Teoria dos Exemplares, Fonética e Fonologia estão interconectadas. 
Também não é possível determinar uma lista de formas subjacentes categóricas, já que a língua é dinâmica, plástica, e as representações e categorias mudam com o uso. Isso justifica nossa escolha, neste artigo, em falar de 'alternância entre monotongo e ditongo' e não em 'fenômeno de monotongação'. O nosso objeto refere-se ao que tradicionalmente é definido como ditongo. Essa definição é, por muitas vezes, arbitrária e não explica adequadamente os fatos da língua. Falemos brevemente do gerativismo. No caso da variação entre ditongos e monotongos, podemos usar regras de inserção e de eliminação, respectivamente. No caso de palavras como 'rapaz, arroz', por exemplo, assumimos que a forma subjacente é o monotongo e o ditongo 'rapaiz' seria resultado de uma regra de inserção (CAGLIARI, 2002). No entanto, em outros casos, quando ocorre a monotongação, como em 'caixa', assumimos como forma subjacente o ditongo. Essas regras precisam, ainda, ser opcionais, pois o falante pode manter o ditongo em 'caixa' ou não produzi-lo em 'rapaz'. O problema que se apresenta é o que definimos como forma subjacente: se, em 'rapaz' e 'arroz', admitimos um monotongo na forma subjacente, por que, em contrapartida, assumimos um ditongo em palavras, como 'demais' e 'depois', que se encontram também em contextos tônicos e seguidos de fricativa alveolar, e cujo ditongo, em alguns dialetos do português, varia com um monotongo (FURLAN, 1989; BRESCANCINI, 2009; HAUPT, 2011)?

A questão da arbitrariedade da forma subjacente é criticada por Bybee (2001) ao defender uma fonologia baseada no uso. Numa proposta baseada no uso, o ditongo ou monotongo emergirá das experiências do falante, isto é, o armazenamento em redes por similaridade fonética e semântica decorrentes da frequência de ocorrência permitirá a emergência de um ditongo ou monotongo e a generalização do seu uso (considerem-se as nuvens de exemplares, nas quais os exemplares mais usados vão adquirindo força). Daí a importância de considerarmos a palavra como foco de análise da variação fonéticofonológica. Por isso, apresentamos, na seção a seguir, dados sobre a frequência de palavras com a sequência tradicionalmente denominada como ditongo decrescente com a semivogal alta anterior para tecer mais alguns comentários sobre essa questão. Apresentamos também um resumo de alguns estudos já feitos sobre o uso variado do ditongo e monotongo para discutir os resultados dos fatores linguísticos usualmente analisados.

\section{Os dados ${ }^{1}$}

Os estudos apresentados são de cunho variacionista, no qual são considerados como condicionantes do fenômeno tanto fatores linguísticos quanto extralinguísticos, sociais. Entre os estudos feitos em sílabas abertas, citamos Amaral (2005); Silva (2004); Lopes (2002); Araújo (1999); Paiva (1996) e Cabreira (1996). Em sílabas fechadas, consideramos o estudo de Brescancini (2009). A partir dessa revisão, elaboramos um quadro resumo dos fatores linguísticos que favorecem e desfavorecem o apagamento da semivogal [I] em sílabas abertas.

Quadro 1 - Resumo das variáveis linguísticas envolvidas no fenômeno da monotongação em estudos já realizados

\begin{tabular}{|c|c|c|}
\hline \multicolumn{2}{|r|}{ Fator } & Considerações (favorável ou desfavorável à monotongação) \\
\hline \multirow{8}{*}{$\begin{array}{l}\text { Contexto } \\
\text { seguinte }\end{array}$} & Tepe $[r]$ & Favorável em todos os estudos \\
\hline & Fricativa palato-alveolar $\left[\int\right]$ & Favorável em todos os estudos, com exceção de Araújo (1999) que a considerou neutra em relação ao ditongo [eI] \\
\hline & Fricativa palato-alveolar [3] & $\begin{array}{l}\text { Favorável em todos os estudos, com exceção de Araújo (1999) que a considerou desfavorável em relação ao } \\
\text { ditongo [eI] }]\end{array}$ \\
\hline & Fricativas alveolares [s, z] & Desfavorável em todos os estudos \\
\hline & Nasais $[\mathrm{m}, \mathrm{n}]$ & Desfavorável em todos os estudos \\
\hline & Laterais $[l, \Lambda]$ & Desfavorável em todos os estudos. \\
\hline & Oclusivas [p, b, t, d, k, g] & Desfavorável em todos os estudos. Somente ocorre a monotongação na palavra manteiga \\
\hline & Vogais & A vogal [a] foi considerada favorável no estudo de Amaral (2005) em relação ao ditongo [e I $]$. \\
\hline \multirow[t]{2}{*}{ Tonicidade } & Tônica & Favorável para Araújo (1999) e Paiva (1996). \\
\hline & Átona & Favorável para Amaral (2005) e Silva (2004) - sílabas pretônicas. \\
\hline \multirow{2}{*}{$\begin{array}{l}\text { Status } \\
\text { morfológico }\end{array}$} & Radical & Favorável para Cabreira (1996) e Lopes (2002). \\
\hline & Sufixo & Favorável para Paiva (1996). \\
\hline \multirow[t]{5}{*}{ Outros } & Palavras comuns & As palavras de uso mais corriqueiro favorecem o fenômeno; variável considerada por Lopes (1999) \\
\hline & Velocidade de fala & Velocidade rápida favorece a monotongação; variável considerada por Araújo (1999) \\
\hline & $\begin{array}{l}\text { Posição do elemento } \\
\text { seguinte favorecedor }\end{array}$ & Na sílaba seguinte, a monotongação é favorecida; na mesma sílaba, é inibida; fator considerado por Cabreira (1996) \\
\hline & Classe de palavra & Os não-verbos favorecem a monotongação; variável considerada por Amaral (2005) \\
\hline & Extensão do vocábulo & Palavras monossilábicas desfavorecem o fenômeno; variável considerada por Paiva (1996) \\
\hline
\end{tabular}

Fonte: HAUPT Carine Contribuições da Fonologia de Uso e da Teoria dos Exemplares no fenômeno da monotongação. Revista Estudos da Linguagem, Belo Horizonte v. 19, n. 1, p. 167-190, jan./jun. 2011

\footnotetext{
Os dados descritos neste artigo foram levantados e usados para a análise do fenômeno de monotongação na fala dos florianopolitanos na pesquisa de doutorado da autora.
} 
Conforme o Quadro 1, podemos ver que o contexto seguinte constituído de consoante palato-alveolar e tepe são fatores foneticamente condicionantes para a monotongação. No entanto, não há consenso entre os resultados em relação aos outros fatores, até por que nem todos os estudos consideram as mesmas variáveis com todos os ditongos. É o caso da extensão do vocábulo e da classe de palavras, consideradas relevantes por apenas uma autora. Mas, mesmo em variáveis consideradas em todos os estudos como relevantes, ocorrem resultados diferentes: as sílabas tônicas se mostraram favorecedoras da monotongação nos estudos de Araújo (1999) e de Paiva (1996), porém, nos estudos de Amaral (2005) e de Silva (2004), foram as átonas que favoreceram o fenômeno.

Em sílabas fechadas, o fenômeno de monotongação é menos explorado. Na cidade de Florianópolis, ele é mencionado por estudiosos como Furlan (1989) e estudado mais a fundo por Brescancini (2009). Ambos constatam monotongos em sílabas fechadas, tendência contrária ao que diz Cabreira (1996) ao afirmar que, em sílabas fechadas (fator posição do elemento seguinte favorecedor, do Quadro 1), tem-se um ditongo pesado, isto é, um ditongo verdadeiro, que não monotonga. Brescancini (2009) constatou que houve concentração de monotongação em itens específicos, a saber, 'mais', 'depois', 'dois' e 'seis', e, recorrentemente, diante da realização palato-alveolar da fricativa final. No entanto, a monotongação ocorreu também em outros itens lexicais, além dos supracitados, mas com menor frequência. Obteve, como estatisticamente relevantes, a variável papel morfológico de /S/. A redução foi favorecida quando a fricativa final fazia parte da flexão de verbo, como em 'vais'. Já, como flexão nominal, a redução do ditongo foi desfavorecida. Os radicais tiveram comportamento neutro, ou seja, não podem ser considerados nem favorecedores e nem desfavorecedores. A autora conclui o trabalho dizendo que "a redução do ditongo decrescente diante /S/ caracteriza-se como um processo condicionado lexicalmente, mas que ainda apresenta resquícios de condicionamento estrutural, especificamente de cunho morfológico" (BRESCANCINI, 2009, p. 49).

Observando todos esses dados, questionamo-nos: do que decorre a divergência dos resultados dos estudos em sílabas abertas supracitados? Uma hipótese seria que diferentes falantes, de diferentes comunidades, têm diferentes experiências com a língua, o que resultaria

\footnotetext{
1 De acordo com Bisol (1989), há o verdadeiro e o falso ditongo. O primeiro constitui-se daquele ditongo que não monotonga, portanto a semivogal faz parte da forma subjacente; no segundo, a semivogal é apenas uma manifestação de superfície, fonética, e pode ou não ocorrer.

2 Nesse estudo, houve apenas 10 ocorrências de monotongação diante de fricativa alveolar.
}

em diferentes resultados. Além disso, o estudo em sílabas fechadas já evidenciou o papel de determinados itens lexicais para conduzir o uso variado entre ditongo e monotongo ou predominância do uso de um em detrimento de outro. $\mathrm{O}$ mesmo se aplicaria à variação em sílabas abertas. Ao analisar a frequência dos dados de fala em um estudo da variação entre ditongo e monotongo nessas sílabas (HAUPT, 2011), constatou-se que as palavras mais frequentes foram as que tiveram maior número de ocorrências com monotongo e a relevância ou não dos fatores linguísticos, tais como tonicidade, extensão do vocábulo, estiveram atrelados ao fator palavra, isto é, a frequência dos itens lexicais determinou os resultados.

\subsection{Frequência de ocorrência}

Primeiramente, apresentamos as ocorrências dos ditongos decrescentes constituídos da semivogal [I ], foco da presente análise, encontradas no corpus do NILC. Observando a Tab. 1,vemos que o ditongo mais frequente é o ditongo [eI ], seguido do ditongo [aI ], com frequências relativamente próximas. Ocupa a terceira posição de ocorrência o ditongo [oI ]. Os ditongos que apresentam menor frequência de ocorrência são constituídos por vogais abertas $\left[\supset I_{n}, \varepsilon I\right]$ e pela vogal alta posterior [uI ].

Tabela 1 - Frequência de ocorrência de palavras contendo ditongos decrescentes $\left[\mathrm{V}_{\mathrm{I}}\right]$ no corpus do NILC

\begin{tabular}{|c|c|c|}
\hline Ditongo & $\begin{array}{c}\text { Frequência de ocorrência } \\
\text { total no NILC }\end{array}$ & $\%$ \\
\hline [eI $]$ & 484.007 & 39,08 \\
\hline [aI $]$ & 406.198 & 32,79 \\
\hline [OII] & 239.484 & 19,33 \\
\hline [uI ] & $67.560^{*}$ & 5,45 \\
\hline$[\varepsilon I]$ & 32.385 & 2,62 \\
\hline [כI $]$ & 8.980 & 0,73 \\
\hline Total & 1.238 .614 & 100 \\
\hline
\end{tabular}

* Não consideramos as palavras muito/a/os/as, por terem um ditongo nasalizado. Essas palavras somam 51.630 ocorrências.

$\mathrm{Na}$ Tab. 2, apresentamos os itens lexicais com alta frequência de ocorrência no corpus do NILC e seus percentuais em relação ao total das palavras com ditongos. Esclarecemos aqui que dividimos as ocorrências em três grupos, considerando de alta frequência as palavras com até $1 \%$ de ocorrência em relação ao total de itens com ditongo; de frequência moderada as palavras entre $1 \% \mathrm{e}$ $0,1 \%$ do total de itens lexicais com ditongo; e de baixa frequência as palavras com menos de $0,1 \%$ de ocorrência. 
Tabela 2 - Palavras com alta frequência de ocorrência com ditongos [VI9] no corpus do NILC

\begin{tabular}{lcr}
\hline \multicolumn{1}{c}{$\begin{array}{c}\text { Itens lexicais mais } \\
\text { frequentes }\end{array}$} & $\begin{array}{c}\text { Frequência de } \\
\text { ocorrência }\end{array}$ & $\%$ \\
\hline Mais & 158.072 & 12,76 \\
Foi & 117.145 & 9,46 \\
Vai & 42.033 & 3,39 \\
Brasileiro/a/os/as & 41.723 & 3,37 \\
Dois & 41.452 & 3,35 \\
Maior/ES & 35.261 & 2,85 \\
Depois & 34.126 & 2,76 \\
Meio/a/os/as & 27.723 & 2,24 \\
Primeiro/a/os/as & 26.186 & 2,11 \\
Feito/a/os/as & 25.275 & 2,04 \\
Deixar e flexões & 24.612 & 1,99 \\
Dinheiro & 24.532 & 1,98 \\
Feira/s & 20.859 & 1,68 \\
Coisa/s & 19.079 & 1,54 \\
Lei/s & 18.777 & 1,52 \\
Janeiro & 12.869 & 1,04 \\
Pois & 12.822 & 1,04 \\
Noite & 12.544 & 1,01 \\
\hline
\end{tabular}

Da lista apresentada na Tab. 2, percebemos que existe um grande número de palavras ( 9 das 18 palavras, correspondendo a $50 \%$ da lista) com o ditongo [eI] entre as palavras mais frequentes, o que pode explicar o fato de esse ser o ditongo mais frequente (Tab. 1) nesse corpus. $\mathrm{O}$ alto número de ocorrência do ditongo [aI] deve-se, principalmente, à alta frequência de um item lexical específico, a saber, 'mais'. Além dele, apenas outros dois itens contém o ditongo [aI - ' vai' e 'maior'. Nessa lista, ainda encontramos palavras contendo o ditongo [oI], algumas se configurando entre as mais frequentes, como 'foi' e 'dois'. Percebemos também que palavras com desinência verbal e nominal não aparecem com alta frequência no corpus do NILC, salvo 'vai', 'foi' e 'feito', que são formas irregulares dos verbos ir e fazer.

Uma última observação que cabe aqui é que não há palavras com alta frequência de ocorrência com os ditongos [OI ], [EI] e [uI ]. Muitas palavras com esses ditongos apresentam frequência moderada. Em grande parte, as palavras de frequência moderada contém ditongos que se constituem em morfemas de plural formados pelos ditongos $[\mathrm{aI}]$, $[\mathrm{eI}]$ e $[\varepsilon \mathrm{I}]$, e em desinência verbal - [uI]. Observamos também que o ditongo [aI ], quando constitui a desinência de plural, é mais frequente do que o ditongo [eI] com o mesmo status.

A lista de palavras pouco frequentes é bastante extensa e abarca um grande número de palavras que ocorrem apenas uma vez. Em muitas dessas palavras, o ditongo se encontra na desinência de número (-ais, -eis) e na desinência verbal de segunda pessoa do singular e plural de diversos tempos verbais ('apegais', 'abraçai', 'aprovais', 'dancei', 'visitarei', 'fiquei', por exemplo). Essa diferença de frequência de ocorrência de ditongos com status morfológico distinto (daqueles com alta frequência em relação a esses com baixa frequência) pode explicar por que, em alguns estudos, como os de Cabreira (1996) e de Lopes (2002), o radical aparece como variável favorável e o sufixo, como desfavorável, pois, como vimos, as palavras mais frequentes são aquelas em que o ditongo se encontra no radical.

\subsection{Frequência tipo}

Nesta seção, apresentamos os dados referentes à frequência tipo, a partir do corpus do NILC. ${ }^{3}$ Considerando os estudos já feitos, dividiremos a frequência tipo em diferentes tabelas, a fim de dar conta dos diversos fatores estruturais em que o ditongo se encontra, relativos à tonicidade, posição da sílaba na palavra, contexto fonético seguinte e extensão do vocábulo. Primeiramente, apresentamos, na Tab. 3, a distribuição dos ditongos de acordo com o tipo de sílaba. Nas tabelas posteriores, continuaremos a apresentar os tipos nas duas categorias de sílabas separadamente.

Tabela 3 - Frequência tipo de palavras com ditongos distribuída de acordo o tipo de sílaba

\begin{tabular}{|c|c|c|c|c|c|c|}
\hline \multirow{2}{*}{ Ditongos } & \multicolumn{2}{|c|}{ Sílaba aberta } & \multicolumn{2}{|c|}{ Sílaba fechada } & \multicolumn{2}{|c|}{ Total } \\
\hline & Número & $\%$ & Número & $\%$ & Número & $\%$ \\
\hline [aI] & 439 & 7,93 & 745 & 13,46 & 1.184 & 21,39 \\
\hline$\left[\mathrm{e}_{\mathrm{N}}\right]$ & 3.139 & 57,61 & 747 & 13,49 & 3.886 & 70,21 \\
\hline [OII] & 144 & 2,60 & 4 & 0,07 & 148 & 2,67 \\
\hline$[\varepsilon$ I $]$ & 58 & 1,05 & 37 & 0,67 & 95 & 1,72 \\
\hline [OI] & 27 & 0,49 & 4 & 0,07 & 31 & 0,56 \\
\hline [uI] & 189 & 3,42 & 2 & 0,04 & 191 & 3,46 \\
\hline Total & 3.996 & 72,19 & 1.539 & 27,81 & 5.535 & 100 \\
\hline
\end{tabular}

Considerando os totais apresentados na Tab. 3, podemos ver que o ditongo com a maior frequência tipo é o ditongo [eI] $(70,21 \%)$, seguido dos ditongos [aI] $(21,39 \%)$, [uI] $(3,41 \%)$, [uI] $(2,67 \%)$, [ $\varepsilon \mathrm{I}](1,72 \%) \mathrm{e}$ [OI $](0,56 \%)$. Quanto ao tipo de sílaba, verificamos que, em sílabas abertas, o padrão se repete, ou seja, o ditongo [eI ] continua sendo o mais frequente $(57,61 \%)$, seguido dos demais na mesma sequência anterior. Já, nas sílabas fechadas, os ditongos [aI ] $(13,46 \%)$ e [eI ] $(13,49 \%)$

\footnotetext{
3 Muitos trabalhos fazem o levantamento da frequência tipo em dicionários Optamos por um corpus. Portanto, não se encontram, nessa lista, todos os verbetes da língua portuguesa que contêm ditongo. Mas, em compensação, acreditamos que a lista resultante desse levantamento seja mais adequada, uma vez que constam as palavras realmente em uso (tanto as frequentes como as pouco frequentes).
} 
têm praticamente a mesma frequência tipo. Os demais ditongos têm poucos tipos em sílabas fechadas (ficando com frequência tipo abaixo de $1 \%$ ). Com exceção do ditongo [aI], todos os outros ditongos têm maior número de tipos nas sílabas abertas do que nas sílabas fechadas.

Observando a Tab. 4, entendemos um pouco melhor como se dá a distribuição dos ditongos em sílabas abertas e fechadas. O ditongo [aI ], que é o único que possui mais tipos em sílabas fechadas do que em abertas, é bastante produtivo na língua portuguesa como desinência de plural (-ais). Por isso, [aI], em sílabas fechadas, ocorre predominantemente na posição de sufixo $(99,33 \%)$. Além da desinência de plural, esse ditongo ainda pode constituir a desinência verbal que marca a segunda pessoa do plural do presente do indicativo - 'amais', por exemplo. Essa forma está em desuso, principalmente na oralidade, mas ainda é encontrada na modalidade escrita. Como radical, temos apenas 5 tipos para o ditongo [aI] em sílabas fechadas - 'mais', 'jamais', 'demais', 'ademais' e 'cais'.

Em sílabas abertas, os tipos contendo ditongo [aI ] concentram-se no radical $(66,28 \%)$, mas também encontramos bastantes tipos em que o ditongo compõe um sufixo. Esses sufixos referem-se à desinência verbal de formas, tais como 'amai' (imperativo) e 'sobressai' (terceira pessoa do singular do presente do indicativo dos verbos de terceira conjugação). As formas do imperativo, referentes à segunda pessoa do plural, ainda são encontradas nos textos escritos, mas na fala estão em desuso.

Para o ditongo [e $\mathrm{e}$ ] em sílabas fechadas, também temos mais tipos com ditongo compondo sufixos do que radicais. Esses sufixos marcam o plural ('perceptíveis') e a desinência verbal de segunda pessoa do plural em alguns tempos verbais ('fazeis'). Enquanto radical, as ocorrências do ditongo [eI ] resumem-se às palavras 'seis' e 'dezesseis'. Observamos, portanto, que, como sufixos, o ditongo [eI ] e o ditongo [aI ] são igualmente produtivos em sílabas fechadas.

Em sílabas abertas, temos uma concentração do ditongo [eI ] na posição de sufixo $(86,08 \%)$. Isso se deve ao fato de esse ditongo ser parte do sufixo -eiro e ser desinência verbal de primeira pessoa do singular do pretérito perfeito e do futuro do presente - 'comecei', 'começarei'. Os totais referentes a essas duas formas de sufixo são os seguintes: 954 tipos como sufixo -eiro e 1.739 como flexão verbal. Concluímos, a partir disso, que esse ditongo é bastante produtivo na língua portuguesa enquanto sufixo verbal.

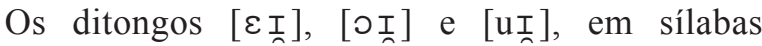
fechadas, ocorrem somente na posição de sufixo como desinência nominal de número. Os ditongos abertos, na maioria, encontram-se no radical. Podemos sintetizar as observações acima, afirmando que os ditongos fechados existem, na língua portuguesa, em quase sua totalidade, como sufixos, nominais ou verbais. Já os ditongos abertos, com exceção do ditongo [e I I], aparecem predominantemente no radical das palavras.

$\mathrm{Na}$ Tab. 5, observamos a distribuição dos ditongos de acordo com a sua tonicidade. A partir dessa tabela e da Tab. 4, em relação aos tipos em sílabas abertas, temos as seguintes constatações: (a) o ditongo [a $\mathrm{a}$ ] tem uma distribuição homogênea entre sílabas tônicas e átonas. Os sufixos verbais e de plural encontram-se em sílabas tônicas, o que sugere que a maioria dos ditongos situados no radical se encontre em sílabas átonas; (b) o tipo mais frequente para o ditongo [e $\mathrm{e}$ ] é o tônico $(87,76 \%) \mathrm{em}$ decorrência dos sufixos, tanto o derivacional-eiro, quanto o flexional -ei, que são tônicos. A partir dos números, infere-se que a maioria dos ditongos que se encontram na posição de radicais são também átonos; (c) o tipo mais frequente para o ditongo [oI ] é o átono (76,39\%).

Tabela 4 - Frequência tipo de palavras com ditongos distribuída de acordo com o status morfológico

\begin{tabular}{|c|c|c|c|c|c|c|c|}
\hline & \multirow{2}{*}{ Sílaba } & \multicolumn{2}{|c|}{ Radical } & \multicolumn{2}{|c|}{ Sufixo/Desinência } & \multicolumn{2}{|c|}{ Total } \\
\hline & & Número & $\%$ & Número & $\%$ & Número & $\%$ \\
\hline \multirow{2}{*}{ [aI $]$} & Aberta & 291 & 66,28 & 148 & 33,72 & 439 & 7,93 \\
\hline & Fechada & 5 & 0,67 & 740 & 99,33 & 745 & 13,45 \\
\hline \multirow{2}{*}[\mathrm{e}_{\mathrm{N}}]{} & Aberta & 437 & 13,92 & 2.702 & 86,08 & 3.139 & 56,71 \\
\hline & Fechada & 2 & 0,26 & 745 & 99,74 & 747 & 13,49 \\
\hline \multirow{2}{*}{ [OI] } & Aberta & 142 & 98,60 & 2 & 1,40 & 144 & 2,60 \\
\hline & Fechada & 3 & 75,00 & 1 & 25,00 & 4 & 0,07 \\
\hline \multirow{2}{*}[\varepsilonI]{} & Aberta & 47 & 81,03 & 11 & 8,97 & 58 & 1,04 \\
\hline & Fechada & 0 & 0 & 37 & 100 & 37 & 0,66 \\
\hline \multirow{2}{*}{ [OI $]$} & Aberta & 22 & 81,4 & 5 & 8,52 & 27 & 0,48 \\
\hline & Fechada & 0 & 0 & 4 & 100 & 4 & 0,07 \\
\hline \multirow{2}{*}[\mathrm{UI}_{\mathrm{I}}]{} & Aberta & 136 & 71,95 & 53 & 28,05 & 189 & 3,41 \\
\hline & Fechada & 0 & 0 & 2 & 100 & 2 & 0,03 \\
\hline Total & & 1.085 & 19,60 & 4.450 & 80,40 & 5.535 & 100 \\
\hline
\end{tabular}


Tabela 5 - Frequência tipo de palavras com ditongos distribuída de acordo com a tonicidade.

\begin{tabular}{|c|c|c|c|c|c|c|c|}
\hline & \multirow{2}{*}{ Sílaba } & \multicolumn{2}{|c|}{ Tônica } & \multicolumn{2}{|c|}{ Átona } & \multicolumn{2}{|c|}{ Total } \\
\hline & & Número & $\%$ & Número & $\%$ & Número & $\%$ \\
\hline \multirow{2}{*}[aI]{} & Aberta & 216 & 49,20 & 223 & 50,80 & 439 & 7,93 \\
\hline & Fechada & 745 & 100 & 0 & 0 & 745 & 13,45 \\
\hline \multirow{2}{*}{ [eI $]$} & Aberta & 2.755 & 87,76 & 384 & 12,24 & 3.139 & 56,71 \\
\hline & Fechada & 116 & 18,38 & 631 & 81,62 & 747 & 13,49 \\
\hline \multirow{2}{*}{ [OI] } & Aberta & 34 & 23,61 & 110 & 76,39 & 144 & 2,60 \\
\hline & Fechada & 3 & 75,00 & 1 & 25,00 & 4 & 0,07 \\
\hline \multirow{2}{*}[\varepsilonI]{} & Aberta & 58 & 100 & 0 & 0 & 58 & 1,04 \\
\hline & Fechada & 37 & 100 & 0 & 0 & 37 & 0,66 \\
\hline \multirow{2}{*}{ [OI ] } & Aberta & 23 & 85,18 & 4 & 14,82 & 27 & 0,48 \\
\hline & Fechada & 4 & 100 & 0 & 0 & 4 & 0,07 \\
\hline \multirow{2}{*}[\mathrm{uI}_{\mathrm{N}}]{} & Aberta & 47 & 24,86 & 142 & 75,14 & 189 & 3,41 \\
\hline & Fechada & 2 & 100 & 0 & 0 & 2 & 0,03 \\
\hline Total & & 4.040 & 72,99 & 1.495 & 27,01 & 5.535 & 100 \\
\hline
\end{tabular}

Considerando-se que esse ditongo ocorre quase na sua totalidade no radical da palavra, temos, novamente, uma concentração maior de sílabas átonas para esse contexto; (d) o ditongo [uI ] mais frequente é o átono $(75,14 \%)$, que também se associa ao radical das palavras, uma vez que ocorre poucas vezes enquanto sufixo; (e) os demais ditongos $-[\varepsilon I]$ ] e $[\supset I]-$ são predominantemente tônicos.

Em relação às sílabas fechadas, predominantemente desinências, temos as seguintes situações para a tonicidade: (a) o ditongo [aI ] encontra-se sempre em sílaba tônica, pois os sufixos nominais são tônicos; (b) para [eI], há uma maior concentração de tipos com ditongos em sílabas átonas $(81,62 \%)$. No caso desse ditongo, a desinência de plural encontra-se sempre em posição átona (amáveis), ao contrário do que acontece com o ditongo [aI ] ('castiçais') quando nesse tipo de morfema; (c) o ditongo [ $\varepsilon I$ I $]$, que também é desinência de plural, encontra-se em sílaba tônica; (d) os demais ditongos, como já constatado, ocorrem em número muito reduzido em sílabas fechadas e essas poucas ocorrências, por sua vez, são tônicas.

Vemos, portanto, que a distribuição dos tipos de acordo com a tonicidade está relacionada com os padrões referentes ao status morfológico, apresentado na Tab. 4. Desse modo, podemos estabelecer as seguintes relações entre esses dois fatores estruturais: as desinências verbais são tônicas; as desinências nominais de número são tônicas para os ditongos [aI] e [ $\varepsilon I]$ e átonas para o ditongo [eI]; situados no radical da palavra, há mais ditongos átonos para todos os tipos de ditongos, com

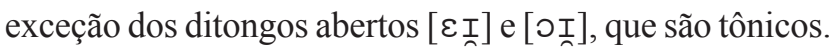
A respeito desse último ditongo, vale esclarecer que as ocorrências em sílabas átonas referem-se às palavras derivadas de itens com [0] tônico, como, por exemplo, 'herói' e 'heroicamente', respectivamente.

Tabela 6 - Frequência tipo de palavras com ditongos distribuída de acordo com a posição silábica do ditongo

\begin{tabular}{|c|c|c|c|c|c|c|c|c|c|}
\hline & \multirow{2}{*}{ Sílaba } & \multicolumn{2}{|c|}{ Posição inicial } & \multicolumn{2}{|c|}{ Posição medial } & \multicolumn{2}{|c|}{ Posição final } & \multicolumn{2}{|c|}{ Total } \\
\hline & & Número & $\%$ & Número & $\%$ & Número & $\%$ & Número & $\%$ \\
\hline \multirow{2}{*}[aI]{} & Aberta & 162 & 37,41 & 157 & 36,25 & 114 & 33,25 & 433 & 7,86 \\
\hline & Fechada & 1 & 0,13 & 0 & 0 & 734 & 99,87 & 735 & 13,35 \\
\hline \multirow{2}{*}[\mathrm{e}_{\text{I}}]{} & Aberta & 155 & 4,94 & 1.439 & 45,91 & 1.540 & 49,13 & 3.134 & 56,93 \\
\hline & Fechada & 0 & 0 & 0 & 0 & 744 & 100 & 744 & 13,51 \\
\hline \multirow{2}{*}{ [OI $]$} & Aberta & 80 & 56,33 & 62 & 43,67 & 0 & 0 & 142 & 2,57 \\
\hline & Fechada & 0 & 0 & 0 & 0 & 2 & 100 & 2 & 0,03 \\
\hline \multirow{2}{*}[\varepsilonI]{} & Aberta & 0 & 0 & 58 & 100 & 0 & 0 & 58 & 1,05 \\
\hline & Fechada & 0 & 0 & 0 & 0 & 37 & 100 & 37 & 0,67 \\
\hline \multirow{2}{*}{ [OI } & Aberta & 2 & 7,69 & 18 & 69,23 & 6 & 23,08 & 26 & 0,47 \\
\hline & Fechada & 0 & 0 & 0 & 0 & 3 & 100 & 3 & 0,05 \\
\hline \multirow{2}{*}{ [UI $]$} & Aberta & 25 & 13,23 & 134 & 70,90 & 30 & 15,87 & 189 & 3,43 \\
\hline & Fechada & 0 & 0 & 0 & 0 & 0 & 100 & 2 & 0,03 \\
\hline Total & & 425 & 7,72 & 1.868 & 33,94 & 3.212 & 58,34 & 5.505 & 100 \\
\hline
\end{tabular}


Na Tab. 6, distribuímos os ditongos quanto à posição da sílaba em que se encontram. Temos totais diferentes em relação às demais tabelas, pois não classificamos os monossílabos. Quanto às sílabas fechadas, temos apenas um tipo em que o ditongo se encontra em sílaba inicial - 'quaisquer'. Os demais tipos encontram-se em sílabas finais. Já em relação às sílabas abertas, temos uma distribuição heterogênea para os diferentes ditongos: (a) para o ditongo [aI ], há uma distribuição equilibrada entre as três posições; (b) para o ditongo [e $\mathrm{I}]$, há predomínio de ditongos em sílabas mediais $(45,91 \%)$, decorrentes do sufixo - eiro, e em sílabas finais $(49,13 \%)$, decorrente dos ditongos que são desinência verbal; (c) o ditongo [oI] ocorre em posição inicial $(56,33 \%)$ e medial $(43,67 \%)$ e os ditongos [EI], [OI ] e [uI ] predominantemente em posição medial, em palavras como 'ideia', 'heroico' e 'constituição'.

Observando a Tab. 7, vemos a frequência tipo dos ditongos distribuída de acordo com a extensão da palavra em que se encontram. Os monossílabos são os menos recorrentes $(0,57 \%)$, tanto para as sílabas fechadas quanto para as sílabas abertas. O padrão mais frequente são as palavras trissílabas e polissílabas para todos os ditongos, com exceção do ditongo $[\varepsilon I]$, em sílabas fechadas, o qual é mais recorrente em palavras dissílabas $(64,86 \%)$. Na Tab. 8 , apresentamos a frequência tipo de palavras com ditongos distribuída de acordo com o contexto seguinte. Nessa tabela, não constam as sílabas fechadas, pois o contexto seguinte é sempre a fricativa sibilante.

Tabela 7 - Frequência tipo de palavras com ditongos distribuída de acordo com a extensão da palavra

\begin{tabular}{|c|c|c|c|c|c|c|c|c|c|c|c|}
\hline & \multirow{2}{*}{ Sílaba } & \multicolumn{2}{|c|}{ Monossílaba } & \multicolumn{2}{|c|}{ Dissílaba } & \multicolumn{2}{|c|}{ Trissílaba } & \multicolumn{2}{|c|}{ Polissílaba } & \multicolumn{2}{|c|}{ Total } \\
\hline & & $\mathbf{N}^{\circ}$ & $\%$ & $\mathbf{N}^{\circ}$ & $\%$ & $\mathbf{N}^{\circ}$ & $\%$ & $\mathbf{N}^{\circ}$ & $\%$ & $\mathbf{N}^{\circ}$ & $\%$ \\
\hline \multirow{2}{*}[aI]{} & Aberta & 6 & 1,36 & 132 & 30,01 & 162 & 36,9 & 139 & 31,66 & 439 & 7,93 \\
\hline & Fechada & 10 & 1,34 & 160 & 21,47 & 258 & 34,63 & 317 & 42,55 & 745 & 13,45 \\
\hline \multirow{2}{*}[\mathrm{e}_{\mathrm{N}}]{} & Aberta & 4 & 0,12 & 381 & 12,13 & 1.262 & 40,2 & 1.492 & 47,53 & 3.139 & 56,71 \\
\hline & Fechada & 3 & 0,40 & 54 & 7,22 & 137 & 18,34 & 553 & 74,02 & 747 & 13,49 \\
\hline \multirow{2}{*}{ [OII] } & Aberta & 2 & 1,39 & 28 & 19,44 & 63 & 43,75 & 51 & 35,41 & 144 & 2,60 \\
\hline & Fechada & 2 & 50,0 & 1 & 25,0 & 25,0 & 0 & 0 & 0 & 4 & 0,07 \\
\hline \multirow{2}{*}[\varepsilonI]{} & Aberta & 0 & 0 & 0 & 0 & 23 & 39,65 & 35 & 60,35 & 58 & 1,04 \\
\hline & Fechada & 2 & 5,41 & 24 & 64,86 & 11 & 29.72 & 0 & 0 & 37 & 0,66 \\
\hline \multirow{2}{*}{ [OI $]$} & Aberta & 2 & 7,40 & 8 & 29,62 & 6 & 22,22 & 11 & 40,74 & 27 & 0,48 \\
\hline & Fechada & 1 & 25,0 & 2 & 50,0 & 1 & 25,0 & 0 & 0 & 4 & 0,07 \\
\hline \multirow{2}{*}[\mathrm{UI}]{} & Aberta & 0 & 0 & 24 & 12,69 & 63 & 33,34 & 102 & 53,97 & 189 & 3,41 \\
\hline & Fechada & 0 & 0 & 2 & 100 & 0 & 0 & 0 & 0 & 2 & 0,03 \\
\hline Total & & 32 & 0,57 & 816 & 14,74 & 1.987 & 35,9 & 2.700 & 48,78 & 5.535 & 100 \\
\hline
\end{tabular}

Tabela 8 - Frequência tipo de palavras com ditongos distribuída de acordo com o contexto seguinte.

\begin{tabular}{|c|c|c|c|c|c|c|c|c|}
\hline & \multicolumn{2}{|c|}{ Vogal } & \multicolumn{2}{|c|}{ Nasal } & \multicolumn{2}{|c|}{ Lateral } & \multicolumn{2}{|c|}{ Tepe } \\
\hline & $\mathbf{N}^{\circ}$ & $\%$ & $\mathbf{N}^{0}$ & $\%$ & $\mathrm{~N}^{\circ}$ & $\%$ & $\mathbf{N}^{\circ}$ & $\%$ \\
\hline [aI] & 118 & 26,87 & 20 & 4,56 & 7 & 1,59 & 28 & 6,38 \\
\hline$\left[\mathrm{e}_{\lambda}\right]$ & 262 & 8,35 & 22 & 0,70 & 5 & 0,15 & 989 & 31,51 \\
\hline [OI $]$ & 33 & 22,91 & 7 & 4,86 & 3 & 2,08 & 12 & 8,34 \\
\hline$[\varepsilon \underset{n}{I}]$ & 48 & 82,75 & 0 & 0 & 0 & 0 & 0 & 0 \\
\hline [OI ] & 6 & 22,23 & 0 & 0 & 0 & 0 & 0 & 0 \\
\hline [UI ] & 5 & 2,64 & 3 & 1,58 & 0 & 0 & 83 & 43,91 \\
\hline \multirow[t]{3}{*}{ Total } & 472 & 11,81 & 52 & 13,01 & 15 & 0,37 & 1.112 & 27,82 \\
\hline & \multicolumn{2}{|c|}{ Fricativa } & \multicolumn{2}{|c|}{ Oclusiva } & \multicolumn{2}{|c|}{ Final } & \multicolumn{2}{|c|}{ Total } \\
\hline & $N^{\circ}$ & $\%$ & $\mathrm{~N}^{\circ}$ & $\%$ & $\mathbf{N}^{\circ}$ & $\%$ & $\mathbf{N}^{\circ}$ & $\%$ \\
\hline [aI] & 95 & 21,64 & 52 & 11,84 & 119 & 27,11 & 439 & 10,98 \\
\hline$\left[\mathrm{e}_{\lambda}\right]$ & 117 & 3,72 & 224 & 7,14 & 1.520 & 48,42 & 3.139 & 78,55 \\
\hline [OI] & 17 & 11,81 & 70 & 48,61 & 2 & 1,39 & 144 & 3,60 \\
\hline$[\varepsilon I]$ & 0 & 0 & 10 & 17,25 & 0 & 0 & 58 & 1,45 \\
\hline [วI] & 1 & 3,70 & 12 & 44,45 & 8 & 29,62 & 27 & 0,67 \\
\hline$\left[\mathrm{UI}_{\mathrm{N}}\right]$ & 29 & 15,34 & 38 & 20,11 & 31 & 16,40 & 189 & 4,73 \\
\hline Total & 259 & 6,48 & 407 & 10,18 & 1.680 & 29,22 & 3.996 & 100 \\
\hline
\end{tabular}


Em relação ao contexto seguinte, apresentado na Tab. 8, constatamos que: (a) para os tipos com o ditongo [aI], prevalecem aqueles seguidos de vogal $(26,87 \%)$ e os que estão no final da palavra $(27,11 \%)$, característica possivelmente decorrente de formas verbais, como cai e caia; (b) para o ditongo [eI], prevalecem os contextos seguintes de tepe $(31,51 \%)$ e final de palavra $(48,42 \%)$. Novamente, temos as desinências verbais influenciando o padrão do contexto seguinte dos ditongos, ao lado do sufixo -eiro; (c) em relação ao ditongo [oI ], vemos o predomínio das oclusivas $(48,61 \%)$ e das vogais $(22,91 \%)$ como contextos seguintes, encontrados no radical das palavras; (d) o ditongo [uI] é, predominantemente, seguido de tepe $(43,91 \%)$ em decorrência das formas verbais de futuro, como 'constituirão', 'constituirá', 'constituirei'; (e) o ditongo [ $\varepsilon$ I $]$ é, na maioria das vezes, seguido de vogal $(82,75 \%)$, mais especificamente da vogal [a], em palavras como 'plateia' e 'ideia'; (f) para o ditongo [OI], o contexto seguinte mais comum é o de consoante oclusiva $(44,45 \%)$, seguido do contexto de final de palavra (16,40\%), como em 'herói' e 'estoico'.

\section{Implicações}

Feita a exposição das frequências de ocorrências e de tipos dos dados do corpus do NILC, cabem alguns comentários. $\mathrm{O}$ primeiro refere-se à comparação entre a frequência de ocorrência e a frequência tipo. Vemos que alguns tipos pouco frequentes apresentam itens lexicais com alta frequência de ocorrência. Verificamos isso, por exemplo, em relação aos monossílabos, para os quais temos um número reduzido de tipos, no entanto alguns deles, como as palavras 'mais', 'vai', 'foi' e 'sei', encontram-se entre as palavras mais frequentes. $\mathrm{O}$ mesmo podemos afirmar acerca do ditongo [oI ]. Dentre os poucos tipos para esse ditongo, alguns, como 'foi', 'depois', 'coisa' e 'noite', têm alta frequência de ocorrência.

O segundo comentário refere-se ao impacto dessas frequências (tipo e de ocorrência) na análise do fenômeno de monotongação em termos de expectativas. Por exemplo, considerando-se os tipos de ditongos em contextos propícios para a monotongação (Tab. 8), podemos prever um maior número de monotongações (em percentuais) para o ditongo $[\mathrm{e} I]$ do que para o ditongo [oI], uma vez que este último apresenta mais tipos com ditongo seguido de vogal e oclusiva (os dois contextos somam $71,52 \%$ dos tipos), contextos não propícios para a redução, conforme atestam os estudos acerca do fenômeno. Por outro lado, a alta frequência de ocorrência de um item lexical também terá seu impacto nos resultados quantitativos ao avaliarmos os fatores estruturais no fenômeno da monotongação, podendo nos dar resultados que não se apliquem a todos os ditongos.
Ao considerarmos, por exemplo, a variável 'tonicidade', a alta frequência de uma palavra como 'coisa', sem contexto propício para a monotongação, poderá contribuir para conduzir o resultado em que as sílabas tônicas desfavorecem o fenômeno, mesmo que esse contexto possa ser favorecedor para o ditongo [eI], uma vez que temos um número alto de palavras com sufixo -eiro, em que o ditongo é tônico e apresenta contexto favorável para a monotongação. Essas observações embasam a nossa hipótese de que os resultados acerca dos contextos estruturais estão associados à palavra, ou seja, à ocorrência de determinados itens lexicais.

Ao tomarmos a palavra como lócus de análise da variação, não há mais a necessidade de pré-estabelecermos variáveis estruturais para o estudo, uma vez que os fatores favoráveis ou desfavoráveis emergirão do uso das palavras em variação, de sua frequência e de sua força nas nuvens de exemplares. Para exemplificar isso, tomemos como exemplo o uso variado de ditongo e monotongo referente ao ditongo [aI] (HAUPT, 2011, p. 97): o uso do monotongo ocorreu quase que exclusivamente em palavras com contexto fonético seguinte de fricativa palato-alveolar, como na palavra 'caixa'. Outros poucos casos ocorreram na palavra 'maior' e no monotongo 'vai'. Considerando o levantamento de tipos feito na seção anterior, concluímos que: os monossílabos serão desfavorecedores e o número de ocorrências de itens lexicais com contexto propício (fricativa palato-alveolar) vai conduzir o resultado para a variável número de sílabas; o status morfológico favorável será o radical, uma vez que as sílabas seguidas de fricativa palato-alveolar pertencem ao radical da palavra; a relação do uso variado do ditongo e monotongo com a variável tonicidade poderá ser significativa, no sentido de as sílabas átonas serem favorecedoras, uma vez que a maior parte dos ditongos em radicais serem átonos. Podemos considerar, então, os resultados acerca dos fatores estruturais como consequência do número de ocorrência dos itens lexicais e não como causa primeira do uso do monotongo.

A nosso ver, partindo da palavra, podemos alcançar conclusões mais precisas, já que temos a vantagem de não anular o papel da força lexical de determinados itens muito frequentes em um fenômeno de variação. Tasca (2005), por exemplo, mesmo fazendo um estudo dentro da metodologia variacionista, percebeu o papel do item lexical ao estudar o uso variado de ditongo e monotongo em sílabas travadas por fricativa sibilante. A autora estabeleceu como fatores linguísticos para o seu estudo a tonicidade, o status morfológico e a vogal de base. Ao rodar os dados, constatou que a vogal baixa era fator favorável. Observou, todavia, que a maioria dos ditongos ocorreu na palavra 'mas'. Ao rodar novamente os dados, excluindo essa palavra, a vogal baixa passou de favorável 
para neutra. Nesse ponto, voltamos para a questão da falta de consenso de resultados de estudos sobre o mesmo fenômeno em diferentes lugares, conforme apresentado na seção 3. Tasca (2005, p. 148) corrobora nossa observação ao dizer que "ainda em relação ao papel da vogal de base, devemos registrar que, não só não houve consenso entre os autores dos estudos anteriormente referidos, como não há consenso entre este estudo e qualquer outro". Partindo da palavra, resolve-se essa questão.

Assim, ao tomarmos a palavra com lócus de análise, juntamente com os pressupostos da Fonologia de Uso e da Teoria dos Exemplares, poderemos entender melhor por que a ocorrência de determinada variação fonológica atinge alguns itens lexicais e outros não, da mesma forma por que uma determinada variável estrutural é favorável ou não, afinal as generalizações emergem do uso de itens lexicais. Por fim, contribuímos também com dados empíricos que evidenciam que a organização do léxico não está separada da gramática, uma vez que a emergência de categorias, como de um ditongo ou monotongo, decorre do uso de itens lexicais que se se organizam em redes e probalisticamente.

\section{Referências}

AMARAL, Maria Porto de. Ditongos variáveis no sul do Brasil. Letras de Hoje, Porto Alegre, v. 40, n. 3, p. 101-106, set. 2005.

ARAÚJO, Maria Francisca Ribeiro de. A alternância de [eI] [e] no português falado na cidade de Caxias, Maranhão. 138f. Dissertação (Mestrado em Linguística) - Instituto de Estudos de Linguagem, Unicamp, Campinas, 1999.

BISOL, Leda. O ditongo na perspectiva atual. D.E.L.T.A., São Paulo, v. 5, n. 2, p. 185-224, 1989.

BRESCANCINI, Cláudia. A redução de ditongos decrescentes seguidos por fricativa em coda no açoriano-catarinense. In: BISOL, Leda; COLLISCHONN, Gisela (Orgs). Português do sul do Brasil: variação fonológica. Porto Alegre: Edipucrs, 2009, p. 34-49.

BYBEE, Joan. The phonology of the lexicon: Evidence from lexical diffusion. In: BARLOW, M. e KEMMER, S. (Orgs) Usage-based models of language. Stanford, 2000, p. 65-85.

BYBEE, Joan. Phonology and language use. Cambridge University Press, 2001.

BYBEE, Joan. Word frequency and context of use in the lexical diffusion of phonetically conditioned sound change. Language Variation and Change, Cambridge University Press, n. 14, p. 261-290, 2002.
BYBEE, Joan. Mechanisms of change in grammaticization: the role of frequency. In: JOSEF, B. D.; JANDA, J. (Org.). The handbook of Historical Linguistic. Oxford: Blackwell, 2003. p. 603-623.

CABREIRA, Sílvio Henrique. A monotongação dos ditongos orais decrescentes em Curitiba, Florianópolis e Porto Alegre. Dissertação de Mestrado. PUC/RS, Porto Alegre, 1996.

CAGLIARI, Luiz Carlos. Análise fonológica: introdução à teoria e prática com especial destaque para o modelo fonêmico. Campinas- SP: Mercado das Letras, 2002.

CRISTOFARO-SILVA, Thaïs; GOMES, Cristina Abreu. Representações múltiplas e organização do componente linguístico. Fórum Linguístico, Florianópolis, v. 4, n. 1 p. 147-177, jul. 2004.

FURLAN, Oswaldo Antônio. Influência açoriana no português do Brasil em SC. Editora da UFSC: Florianópolis, 1989.

HAUPT, Carine. O fenômeno da monotongação dos ditongos [aI, $e I, \quad o I, u I$, , ] 198f. Tese (Doutorado em Linguística) - Programa de Pós-Graduação em Linguística, UFSC, Florianópolis, 2011.

JOHNSON, Keith. The auditory/perceptual basis for speech segmentation. OSU Working Papers in Linguistic. n. 50, p. 101-113, 1997.

LOPES, Raquel. A realização variável dos ditongos low/ e lej/ no português falado em Altamira/PA. $97 \mathrm{f}$. Dissertação (Mestrado em Linguística) - Curso de Pós-Graduação em Letras, Centro de Letras e Artes, UFP, Belém, 2002.

PAIVA, Maria da Conceição Auxiliadora de. Supressão das semivogais nos ditongos crescentes. In: SILVA, Gisele M. de Oliveira; SCHERRE, Maria M. Pereira (Org.). Padrões sociolinguísticos: análise de fenômenos variáveis na cidade do Rio de Janeiro. Departamento de Linguística e Filologia da UFRJ. Rio de Janeiro: Tempo Brasileiro, 1996. p. 219-333.

PIERRENHUMBERT, Janet. Exemplar Dynamics: Word frequency, lenition and contrast. In: BYBEE, J.; HOPPER, P. (Org.). Frequency and the emergence of linguistic structure. Amsterdam: Benjamins, 2000. p. 123-136.

SILVA, Fabiana de Souza. O processo de monotongação em João Pessoa. In: HORA, Demerval da (Org.). Estudos Sociolinguísticos: perfil de uma comunidade. Santa Maria: Palloti, 2004. p. 29-43.

TASCA, Maria. A inserção de glide em sílabas travadas por /S/. Letras de Hoje, Porto Alegre, v. 40, n. 3, p. 137-162, set. 2005.

Recebido: 12 de agosto de 2013

Aprovado: 09 de dezembro de 2013

Contato: carineh@uft.edu.br 